\section{Nach Krebs in Kindheit Risiko für Herzerkrankungen erhöht}

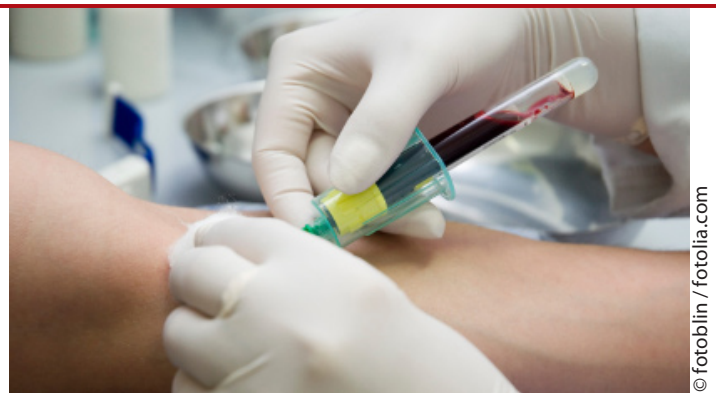

Kardiovaskuläre Risikomarker sollten bei Krebs-Langzeitüberlebenden regelmäßig bestimmt werden.
Auch wenn junge Erwachsene, die im Kindesalter an Krebs erkrankt waren, keine kardiotoxische Therapie erhalten hatten, haben sie häufiger abnorme linksseitige Ventrikelveränderungen und mehr kardiovaskuläre Risikofaktoren als gesunde Geschwister. Das ergab eine US-amerikanische Studie. Viele Patienten mit kardiotoxischer Krebstherapie (z. B. Anthrazykline) weisen als Vorläufer kardialer Erkrankungen subklinische Veränderungen des linken Ventrikels auf. Daher wird für sie eine regelmäßige Herz-Echo-Untersuchung empfohlen. Die neuen Daten sprechen nun für eine routinemäßige Kontrolle bei allen in der Kindheit an Krebs erkrankten Patienten. Verglichen wurden das kardiovaskuläre Risikoprofil und Echobefunde von Krebsüberlebenden mit und ohne kardiotoxische Therapien, deren Krebsdiagnose im Median elf Jahre zurück lag (3-32 Jahre), und gesunden Geschwistern. Bei den 156 Patienten mit kardiotoxischer Therapie waren etwa Masse und Wanddicke des linken Ventrikels vermindert, die linksventrikuläre Nachlast war über die
Norm erhöht. Aber auch die 45 nicht exponierten Überlebenden hatten eine abnormal geringere linksventrikuläre Masse, die Frauen auch eine reduzierte Wanddicke. N-terminales-pro-BNP(NT-proBNP) im Serum war bei beiden Patientengruppen höher als bei den 76 Kontrollpersonen (81,7 und 69,0 vs. 39,4 pg/ $\mathrm{ml})$. Zudem hatten beide Patientengruppen gegenüber den Geschwistern erhöhte Nicht-HDL-Cholesterin(126,5 und 121,1 vs. $109,8 \mathrm{mg} / \mathrm{dl}$ ) und Insulinwerte $(10,4$ und 10,5 vs. $8,2 \mu \mathrm{U} / \mathrm{ml})$. Auch HsCRP als Marker für eine systemische Entzündung war in beiden Patientengruppen ähnlich erhöht.

Um Patienten herauszufiltern, die einer intensiveren Abklärung bedürfen, empfehlen die Studienautoren daher bei allen Langzeitüberlebenden regelmäßig kardiovaskuläre Risikomarker zu bestimmen.

\section{Beate Schumacher}

Lipshultz SE et al. Cardiovascular status of childhood cancer survivors exposed and unexposed to cardiotoxic therapy. J Clin Oncol. 2012;30(10):1050-7.

\title{
$\mu$-Opioid-Rezeptor-Überexpression \\ Ein zusätzlicher Risikofakor für das Fortschreiten von Krebs
}

Die verschiedenen Arten der Anästhesie und der postoperativen Schmerztherapie bei Krebspatienten sind in den vergangenen Jahren wiederholt darauf untersucht worden, wie sie die Rezidivraten und das Metastasierungsrisiko von Malignomen beeinflussen. In den letzten Jahren hatten beispielsweise epidemiologische Studien gezeigt, dass Krebspatienten nach einer Allgemeinanästhesie mit Opioiden höhere Rückfallraten aufwiesen als Patienten, deren Schmerzen lokal oder regional ausgeschaltet worden waren. Weitere Hinweise boten Versuche mit Opiatantagonisten, die gegen die peripheren Nebenwirkungen von Opioiden verabreicht worden waren. Es zeigte sich, dass die betroffenen Patienten länger lebten als solche, die keine Opioidantagonisten erhalten hatten. Nun untersuchten US-amerikanische Forscher den Einfluss bestimmter Allele des $\mu$-OpioidrezeptorGens auf das Überleben von Brustkrebspatientinnen. Speziell war es der A118G-Polymorphismus, ein Single-Nukleotid-Polymorphismus an Position 118 im Codon 40. Bei ihm wird Adenin durch Guanin ersetzt und dadurch Asparagin an einer N-terminalen, extrazellulären Glykosylierungsstelle gegen
Aspartat ausgetauscht. Unter Europäern beträgt die Allelfrequenz etwa $30 \%$. Das G-Allel reduziert die Bindung von Opioiden an den Rezeptor und damit ihre Wirkung. Dies beeinflusst auch die Sterblichkeit bei invasivem Brustkrebs: Bei heterozygoten Trägerinnen des G-Allels ist sie nur halb und bei homozygoten Trägerinnen nur rund ein Drittel so hoch wie bei Frauen mit Brustkrebs, die eine A/A-Konstellation aufweisen. Befunde aus Experimenten mit Zelllinien von nicht kleinzelligem Lungenkrebs geben Anhaltspunkte, wie der $\mu$-Rezeptor am Tumorgeschehen beteiligt sein könnte. In vitro steigerte eine Überexpression des Rezeptors die Aktivität der Enzyme Akt und mTOR sowie die Proliferation und Extravasation bronchoalveolärer Karzinomzellen. In Versuchen mit Mäusen führte dies zu einer 2,5-fach erhöhten Wachstumsrate von Primärtumoren und einer 20fach gesteigerten Metastasierung im Vergleich zur Situation ohne $\mu$-Rezeptor-Überexpression.

\section{Robert Bublak}

Lennon FE et al. The $\mu$-opioid receptor in cancer progression: is there a direct effect? Anesthesiology. 2012;116(4):940-5. 